\title{
IDENTIDADE CORPORATIVA CAMBIANTE E O CONCEITO PRAGMÁTICO DE FIXAÇÃO DAS CRENÇAS
}

\section{CHANGING CORPORATE IDENTITY AND THE PRAGMATIC CONCEPT OF FIXATION OF BELIEF}

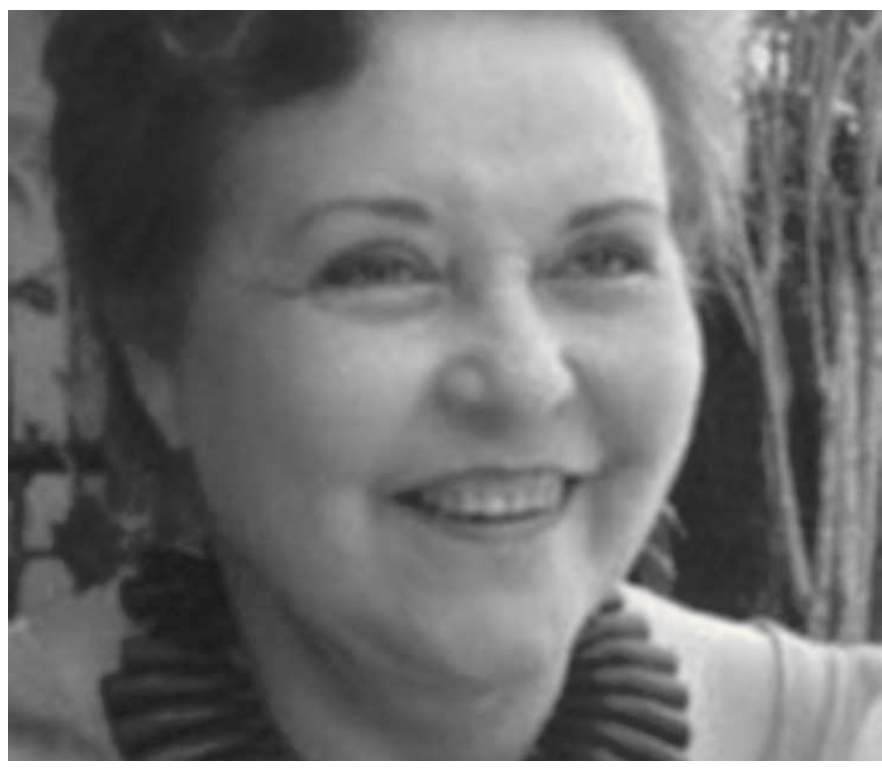

\section{LUCY NIEMEYER}

Doutora em Comunicação e Semiótica pela Pontifícia Universidade Católica de São Paulo. Professora Adjunta da Escola Superior de Desenho Industrial/ Universidade do Estado do Rio de Janeiro.

lucy.niemeyer@gmail.com

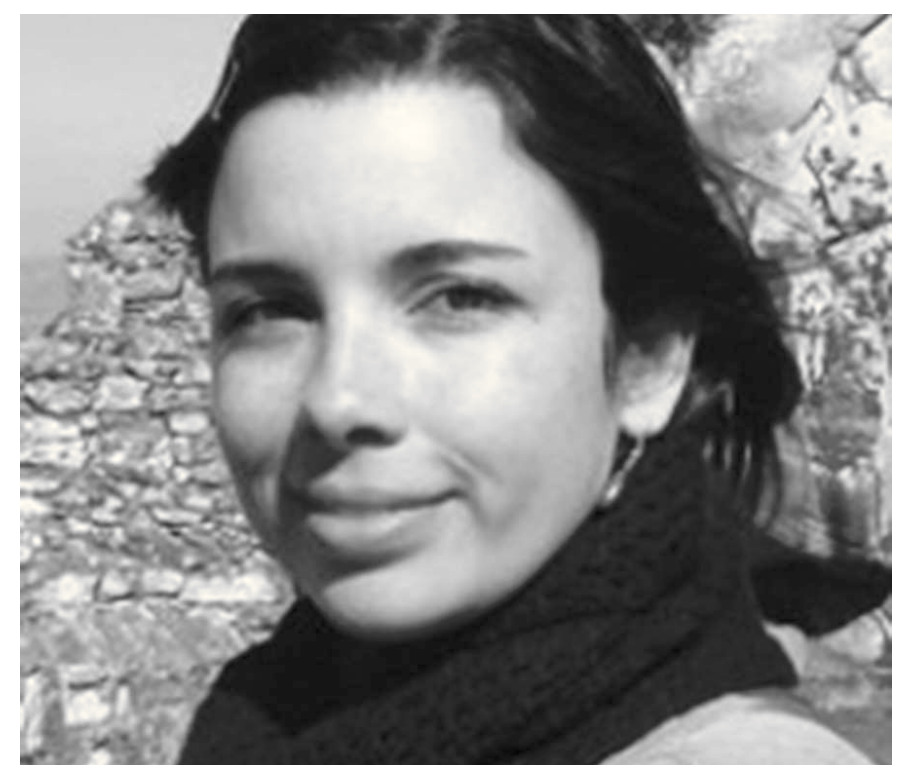

\section{RAQUEL PONTE}

Doutoranda em Design pela Escola Superior de Desenho Industrial da Universidade do Estado do Rio de Janeiro.

Professora Assistente de Comunicação Visual Design/ Universidade Federal do Rio de Janeiro.

raquelponte@globo.com

\section{RESUMO}

Este artigo visa mostrar que a identidade corporativa, além de identificar e diferenciar a empresa e comunicar seus valores, objetiva fixar crenças no público-alvo pelo uso redundante de seus elementos constituintes e pela constante referência ao objeto representado. Com base nos conceitos do 
Pragmatismo de Charles Sanders Peirce, pode-se perceber a importância da fixação das crenças para o estabelecimento de um hábito no consumidor, gerando a fidelização do cliente à empresa.

\section{PALAVRAS-CHAVE}

Design Cambiante. Identidade Corporativa. Fixação das Crenças.

\section{ABSTRACT}

This article presents how corporate identity, besides identifying and distinguishing the company and communicating its values, fixes beliefs in target by the redundant use of its component elements and by constant indication of the object represented. Based on Charles Sanders Peirce's Pragmatism, it is possible to comprehend the importance of fixation of beliefs to establish a habit of conduct in consumer. By this means the client becomes loyal to the company.

\section{KEYWORDS}

Changing Design. Corporate Identity. Fixation of Belief.

\section{INTRODUÇÃO}

Um dos principais campos de atuação do designer é a criação de identidades visuais. Elas visam, por meio de um logotipo ou de uma assinatura visual, de um alfabeto e de cores institucionais (STRUNCK, 1989), gerar uma identificação do consumidor com uma determinada empresa. A identidade visual, portanto, busca transmitir os conceitos, os valores e a missão de uma marca, materializados em formas, cores, texturas, linhas etc.

Segundo o filósofo americano Charles Sanders Peirce (1839-1914), um signo é aquilo que está no lugar de alguma coisa, representando-a. Portanto, podemos compreender a identidade visual como um signo que representa o branding de uma empresa, seu objeto. Nessa semiose são gerados efeitos na mente do consumidor - interpretantes - que dependem dos filtros psicológicos, culturais e emocionais deste destinatário (NIEMEYER, 2007, p.27). Nesse processo semiótico, a empresa visa se identificar para seu público-alvo, se diferenciando de seus concorrentes, marcando um posicionamento claro dentro do mercado. 
Uma das estratégias adotadas pelas empresas consiste no desenvolvimento de uma identidade visual fixa, cujas possibilidades de aplicação de seus elementos aparecem descritas em um manual de identidade visual. Assim, independentemente do suporte da divulgação (papelaria, web, frota, mídias impressas e outras), consegue-se materializar o projeto do logotipo ou da assinatura visual, mantendo suas características e proporcionando, assim, a uniformidade das cores, das formas e das relações entre os elementos, obtendo-se a coerência interna da identidade visual. Espera-se, com essa padronização da aplicação, fidelizar a marca na mente dos clientes pela formação de um hábito de consumo.

Pelo pragmatismo peirciano, entende-se que há a tendência mental de fixar crenças e extirpar dúvidas. Desta maneira, uma empresa busca fortalecer o hábito de seus consumidores, apresentando sempre os mesmos elementos gráficos, para que, rapidamente, esses identifiquem os elementos da identidade visual como representações do conjunto de conceitos de marca. Qualquer aplicação inapropriada como, por exemplo, uma cor mal reproduzida, pode romper com a expectativa do consumidor, gerando dúvidas pela incoerência entre o signo e o objeto. A fixação das crenças, portanto, é algo desejável pelas empresas na comunicação de suas marcas, pois mantém o indivíduo pronto para o consumo. Mas, isso só ocorrerá se ele tiver uma percepção positiva da marca que é comprovada na prática. Assim, a relação entre satisfação, consumo, identidade visual e conceitos da marca será fortalecida e o consumidor, fixando essa crença, se tornará prédisposto a repetir seu consumo.

Há, porém, uma possibilidade dentro do design que rompe os preceitos de fixidez valorizados pelo Alto Modernismo: um design que visa ser mutável, adaptável, e que pode ser percebido tanto em projetos editoriais, quanto em identidades visuais. Rudinei Kopp (2004) nomeia essa vertente como "design cambiante" e a contextualiza dentro da história do design, mostrando suas especificidades de projeto. O que esse artigo apresenta é um questionamento a respeito da possibilidade de uma identidade visual cambiante também fixar crenças nos consumidores, uma vez que seus elementos constituintes são mutáveis e apresentados de forma diferente a cada aplicação. 


\section{IDENTIDADE VISUAL E FIXAÇÃO DAS CRENÇAS}

A identidade visual consiste no resultado de um projeto de design que busca traduzir os conceitos de uma empresa ou de uma marca em signos visuais. Para isso, o designer desenvolve um logotipo ou uma assinatura visual (composta de logotipo e símbolo) para transmitir, por meio de sua forma, cores, texturas e outros aspectos, o posicionamento que a empresa pretende firmar no mercado. Além desses elementos básicos, também podem ser criados elementos secundários, como alfabetos e cores institucionais.

No manual de aplicação da marca são definidas todas as possibilidades de apresentação dessa identidade visual. Podemos ver nas figuras, retiradas do guia da marca da empresa Vale, alguns exemplos dessas regras que visam sua aplicação e apresentação coerente: (a) há o espaço de arejamento que se deve dar em torno da marca para manter sua unidade visual na aplicação; (b) a redução máxima que a marca suporta para sua boa leitura (Fig.1); (c) os modos de cor utilizados na assinatura visual, para permitir que se obtenha o mesmo resultado em diversos suportes e processos gráficos (Fig.2); (d) as famílias tipográficas desenvolvidas (Fig.3), e (e) a coerência visual que deve ser alcançada independentemente das múltiplas possibilidades de aplicação da marca Vale (Fig. 4).

Fig. 1 : Arejamento e redução.

\section{Marca Vale \\ Arejamento e \\ redução}

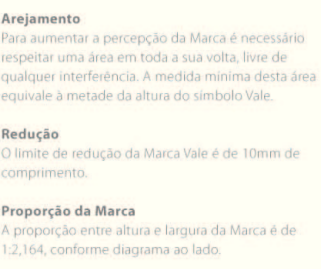

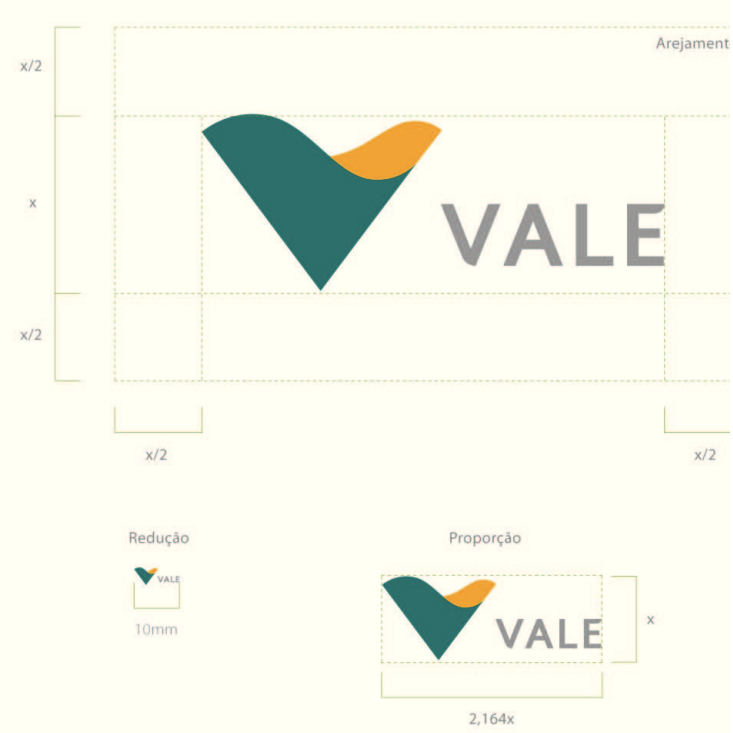

Fonte: Manual de aplicação da marca Vale (p.9). 
Fig. 2: Padrões cromáticos.

Sistema Visual

Padrões cromáticos - Cores Vale

Especificaçōes técnicas

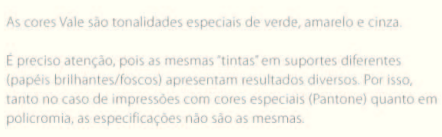

Uso de cores
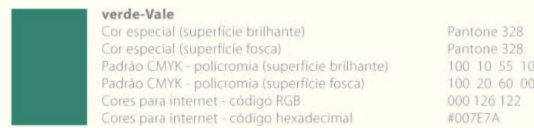

A nova identidade
valores globais.

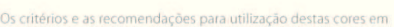

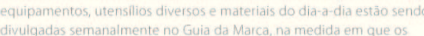
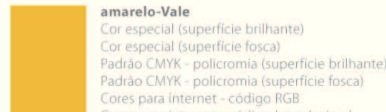

Pantone 124
Pantone 7400
003010008
00201000
23717717
73 ECB11F

Diante da necessidade imediata de substifuir materiais, recomendamos

"migrar" para nosss"s

1. Nenhuma das cores deve ser utilizada excessivamente, nem mesm

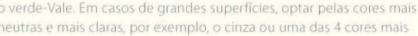

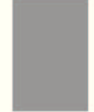

cinza-Vale

2.A maioria destas peças nảo deve receceber a Marca Vale, em especial

aquelas sujeitas a sujeira ou degradaçá. Capachos, por exemplo, nào

ser cinza ou em uma das cores INI ERMMEDIABRIAS das 4 paleteras semi

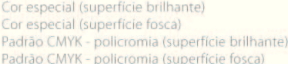

Fonte: Manual de aplicação da marca Vale (p.24).

Fig. 3: Padrões tipográficos.

Sistema Visual

Padrões tipográficos
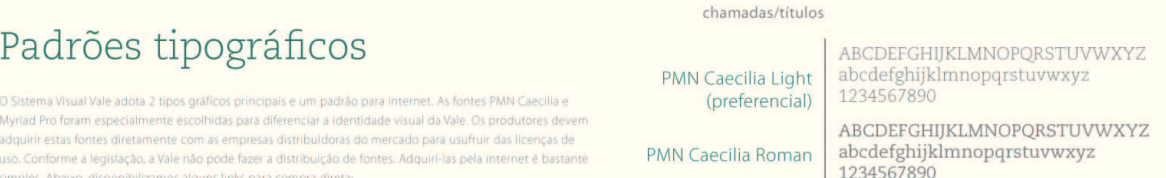

PMN Caecilia Roman

- Pela Adobe Fonts:

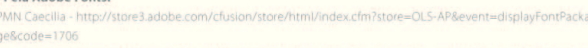

PMN Caecilia Bold abcdefghijklmnopqrstuvwxyz 1234567890

ABCDEFGHIJKLMNOPORSTUVWXYZ

$t=216$

Pela Fonthaus - licensa para 5 computadores

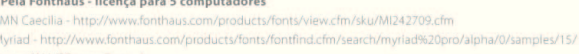

Pela fonts.com- licenca para 5 computadores

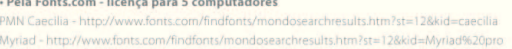

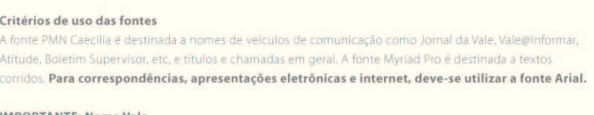

IMPORTANTE: Nome Vale

maísculas

Nomes de instituiçoes e linhas de negócios

FUNDAÇĀO VALE

COBRE

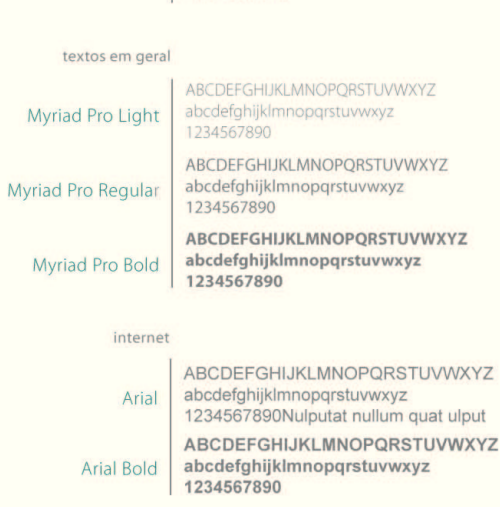

Fonte: Manual de aplicação da marca Vale (p.26). 
Fig. 4: Aplicação da marca.

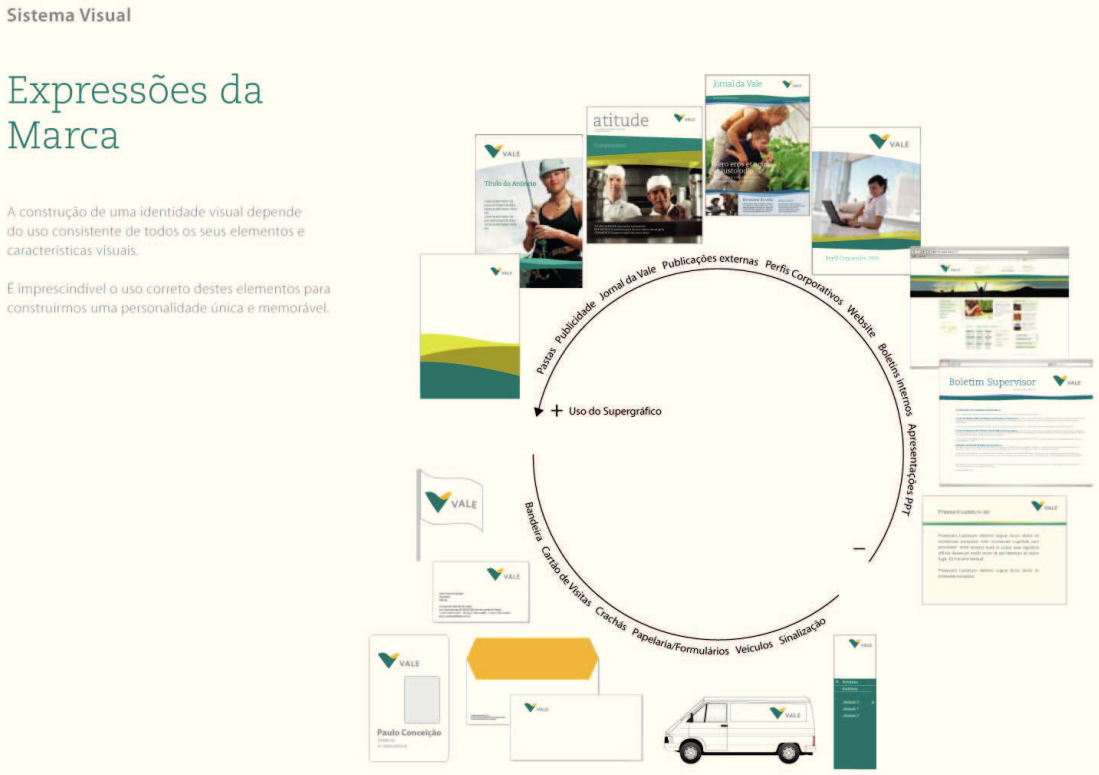

Fonte: Manual de aplicação da marca Vale (p.18).

Podemos perceber como os elementos descritos nas três primeiras figuras (Fig. 1, 2, 3), que tratam de marca, tipografia e cores, formam uma unidade visual quando da sua aplicação em diferentes manifestações da marca, como frota, papelaria e website entre outras (Fig. 4). Como está escrito no manual da marca Vale sobre as expressões da marca, "A construção de uma identidade visual depende do uso consistente de todos os seus elementos e características visuais. É imprescindível o uso correto destes elementos para construirmos uma personalidade única e memorável". Essa padronização dos elementos básicos e secundários contribui para a fixação das crenças no consumidor (PONTE, 2009).

Segundo Peirce, a crença é um estado de tranquilidade do qual não desejamos sair, enquanto a dúvida consiste em um estado de insatisfação do qual lutamos para escapar, procurando voltar à crença. Quando rompese uma crença, a dúvida nos estimula a procurar uma nova, pois é ela que irá nos manter preparados para agir quando a ocasião necessitar. Desenvolver um hábito de ação contribui para facilitar nossa adaptação no mundo, pois otimiza nossas decisões. Se tivéssemos que, a todo momento e a todo estímulo, avaliar a totalidade das variáveis para tomar uma simples decisão, 
não conseguiríamos responder rapidamente quando o estímulo aparecesse a nós. À medida que um determinado estímulo se repete, passamos a notar uma regularidade e acreditamos que ele ocorrerá novamente. Passando a prevê-lo, nos tornamos aptos a responder de forma mais eficiente.

Essa capacidade decorre de o próprio universo também ter hábitos e de eles terem uma generalidade que pode ser interpretada. Um agricultor, por exemplo, se pauta nos horários do sol e nas estações do ano, prevendo-os, para determinar o cultivo de sua lavoura. A sua crença nessa regularidade da natureza que foi estabelecida a partir da observação dos fenômenos determina seu modo de ação e ela é fixada cada vez que os dados observados condizem com essa crença. Se houver uma alteração meteorológica imprevista, essa crença se rompe e estabelece-se uma dúvida, que o paralisará por um tempo até que uma nova crença se instaure. $O$ fim da dúvida, portanto, consiste no estabelecimento de uma opinião. Quando acreditamos em algo $\nabla$ e crença não significa acreditar necessariamente em algo verdadeiro, mas tomar algo por verdadeiro $\bigotimes$ isso se reflete nos nossos atos. Por isso há uma diferença prática entre dúvida e crença, pois esta última "[...] guia nossos desejos e molda nossas ações" (PEIRCE, 1877, p.4).

No pragmatismo peirciano, há um conceito importante que deve ser explicado para a compreensão da relação entre crença e ação: o Sinequismo ou a Doutrina do Continuum. Para Peirce, há uma continuidade entre crença (pensamento) e ação. Por isso, pode-se compreender esta última como o aspecto exterior das ideias. O lado interior, pensamento, e o lado exterior, ação, portanto, não devem ser vistos como pólos opostos, mas como adjacências contínuas. Desta forma, a ação pode ser entendida como um estágio do pensamento, mas não como seu fim, pois um pensamento tem como fim uma ação que tem como fim um pensamento e assim por diante. Compreendendo essa conexão entre pensamento e ação, podemos entender o porquê das identidades visuais buscarem fixar crenças na mente dos consumidores.

Como já foi visto, a identidade visual pode ser entendida, enquanto signo, como a representação dos valores e conceitos de marca de uma empresa. Ampliando um pouco mais essa compreensão, entendendo-a sob a ótica do Sinequismo e do Pragmatismo peirciano, ela pode ser compreendida como a exteriorização de um conceito ou pensamento. Ela consiste, portanto, na materialização do lado interno no mundo da existência 
(lado externo). O desenvolvimento de uma identidade visual coerente, pela manutenção de um padrão de aplicação descrito em seu manual de marca, contribui para fixar as crenças no consumidor.

Com o hábito de se observar um logotipo ou uma assinatura visual, faz-se a conexão entre a representação visual da empresa e seus valores, gerando uma crença no consumidor que aquele signo consiste em marca ou representação daquela empresa. Caso haja uma aplicação consistente dos elementos de identidade visual nos diversos suportes, há a fixação dessa crença, pois o que o consumidor espera encontrar em sua previsão é confirmado pela aplicação correta de tipografia, cores e logotipo ou assinatura visual. A má aplicação - uma falta de fidelidade de cores, uma distorção do logotipo, ou o uso incorreto da família tipográfica, por exemplo \ gera uma dúvida no consumidor, que passa a se questionar se esta marca mal aplicada é de fato a representação daquela empresa que ele conhecia.

Essa inconsistência entre a crença do público-alvo e a aplicação da identidade visual é algo que uma empresa deseja evitar, pois qualquer marca deseja se fortalecer na mente do consumidor. Quando este espera confirma o hábito de encontrar determinada representação e é surpreendido com outro signo, isso acaba por enfraquecer a experiência com a identidade visual. Isto decorre também do fato desse signo ser um símbolo, isto é, sua interpretação depende da convencionalidade e do hábito. Qualquer quebra desse hábito enfraquece a conexão entre o signo e o seu objeto, pois será pela familiaridade que o consumidor poderá correlacionar, por exemplo, a tipografia institucional aos valores de uma empresa. A identidade corporativa, portanto, normatizando suas aplicações possíveis por meio de um manual, visa instaurar uma redundância na experiência pelo uso constante dos seus elementos.

A relação entre crença e ação também pode ser vista na reação do consumidor à identidade visual. Quando este tem uma recepção favorável a uma empresa, por causa de experiências positivas anteriores com seus produtos e serviços $\nabla$ a experiência do uso do serviço ou produto também valida ou não a representação da marca em relação aos valores da empresa -, há o fortalecimento da crença de que, cada vez que ele se relacionar com essa marca, poderá novamente vivenciar experiências que julga serem positivas. Assim, a fixação da crença decorrente da correta aplicação de sua identidade visual conduz a um hábito de conduta que a empresa deseja: o 
consumo. "Por exemplo, em um momento de escolha em um supermercado, espera-se que o público fiel a uma marca compre de imediato seu produto preferido, sem entrar em novas especulações, escolhas e decisões a cada renovação dessa experiência" (PONTE, 2009).

Uma questão importante a ser abordada é que há projetos de design que visam fixar crenças, como o desenvolvimento de uma identidade visual, e outros em que se busca romper com hábitos, como em projetos mais inovadores. As peças de design que se pautam na convencionalidade visam uma situação de tranquilidade e de crença, enquanto as muito originais quebram expectativas, demandando um aprendizado para sua compreensão. A aprendizagem, portanto, decorre do rompimento de crença e hábitos de conduta, que necessitarão da criação de novas crenças e hábitos. Por isso, qualquer peça de design que tenha maior originalidade gera maior dificuldade de interpretação.

Há um tipo de design que rompe com a rigidez das normas de aplicação e que passou a ser mais utilizado no final do século $X X$, sendo nomeado de design cambiante por Kopp (2004). A questão que se coloca é como a identidade visual que, principalmente com o alto modernismo, passou a apresentar uma série de regras como pré-requisitos para sua boa apreensão, pode fixar crenças em seus consumidores mesmo apresentando uma versatilidade nas suas aplicações.

\section{DESIGN CAMBIANTE}

Segundo Kopp (2004), o design que ele propõe chamar de cambiante não se restringe à pós-modernidade em seus estereótipos de efemeridade, de caos e de ecletismo que se contrapõem à hierarquização e à legibilidade do design moderno. Ele transita desde o movimento De Stijl até o Retro (KOPP, 2004) e pode ser entendido como um design flexível ou mutante: "cambiante é então aquilo que varia, que troca, que não é fixo, que barganha, que se transforma". Porém, ainda que o autor não restrinja o design cambiante à pósmodernidade, porque esse modo de trabalhar era comum até 1940, sendo superado no alto modernismo, podemos perceber que, a partir da década de 1970, ele começa a ser praticado com mais força e intencionalidade. Isso pode decorrer de alguns fatores: (1) a mudança nos processos de produção no capitalismo tardio; (2) a inserção do computador na criação das peças de design, e (3) a transformação estética do final do século XX. 
De acordo com David Harvey (2007, p.135), o sistema fordista já dava indícios de esgotamento em meados da década de 1960, pois apresentava um grande problema: rigidez. Havia rigidez nos investimentos para a produção em massa, que presumia um mercado crescente e não saturado, como de fato ocorria, e que dificultava a flexibilização da produção. Havia também rigidez nos mercados e nos contratos de trabalho. Esses problemas foram contornados com a passagem do fordismo para a acumulação flexível, que possibilitou o surgimento de novos setores de produção e o desenvolvimento principalmente do de serviços e a flexibilização dos contratos de trabalho e da produção, que pôde atender sob demanda, dentro de um movimento que Harvey (2007) chama de "compressão espaço-tempo", decorrente da comunicação por satélite que diminui o tempo e aproximou distâncias.

$\mathrm{Na}$ acumulação flexível, o enfoque são as necessidades e os desejos do cliente e não apenas dar vazão à produção em massa. Por isso a flexibilidade nas relações de trabalho também tornou-se tão importante, pois as empresas precisavam se adaptar rapidamente às mudanças. A diferenciação e a possibilidade de personalização dos produtos, atendendo a essas necessidades individuais, foi uma resposta à crise ocorrida na década de 1970. A implementação da estratégia da obsolescência programada [1] por parte de empresas que desejavam maximizar o lucro (GONÇALVES JÚNIOR \& FERREIRA, 2009) acelerou o ciclo de vida de produtos e serviços e os modismos passaram a ser acompanhados, para que as empresas pudessem atender 0 movimento de seus consumidores. A estética estável do alto modernismo deu lugar "a todo o fermento, instabilidade e qualidades fugidias de uma estética pós-moderna, que celebra a diferença, a efemeridade, o espetáculo, a moda e a mercadificação de formas culturais" (HARVEY, 2007, p.148).

A estética de uma época também pode ser influenciada pelas inovações tecnológicas e modos de produção de uma profissão. No caso do design, o surgimento dos aparelhos eletrônico-digitais da marca Macintosh, em 1984 (POYNOR, 2010), permitiu a incorporação de vários processos analógicos antes separados pela possibilidade de digitalização. O programa Desktop Publishing e os softwares baseados em WYSIWYG (what you get is what you see) possibilitaram maior maleabilidade na composição e controle do resultado final, por parte do designer. As novas ferramentas diminuíram a dependência da criação dos processos gráficos menos flexíveis, como a tipografia, por exemplo. Os processos de impressão até a década de 1960 também se 
baseavam no modelo fordista e a sua rigidez, aplicada à produção em larga escala, orientava a criação de layouts que se ajustassem a eles. Portanto, a demanda cada vez maior pela personalização dos produtos e serviços e a flexibilização da criação dos layouts, após o advento do computador, permitiram que o design cambiante ganhasse ainda mais força a partir da década de 1970.

Kopp (2004) cita alguns exemplos de design cambiante para ilustrar sua ideia. A revista americana Ray Gun, a partir da concepção do designer David Carson, que fez sua direção de arte de 1992 a 1996, usou e abusou de experimentações, de falta de padronizações e de ilegibilidade. Californiana, voltada para um público-alvo jovem de conteúdo rock n'roll, mudava o layout interno das páginas de uma reportagem a outra e não seguia regras na confecção das capas de um número para seu subsequente (Fig. 5).

Fig. 5: Capa e páginas internas da revista Ray Gun.
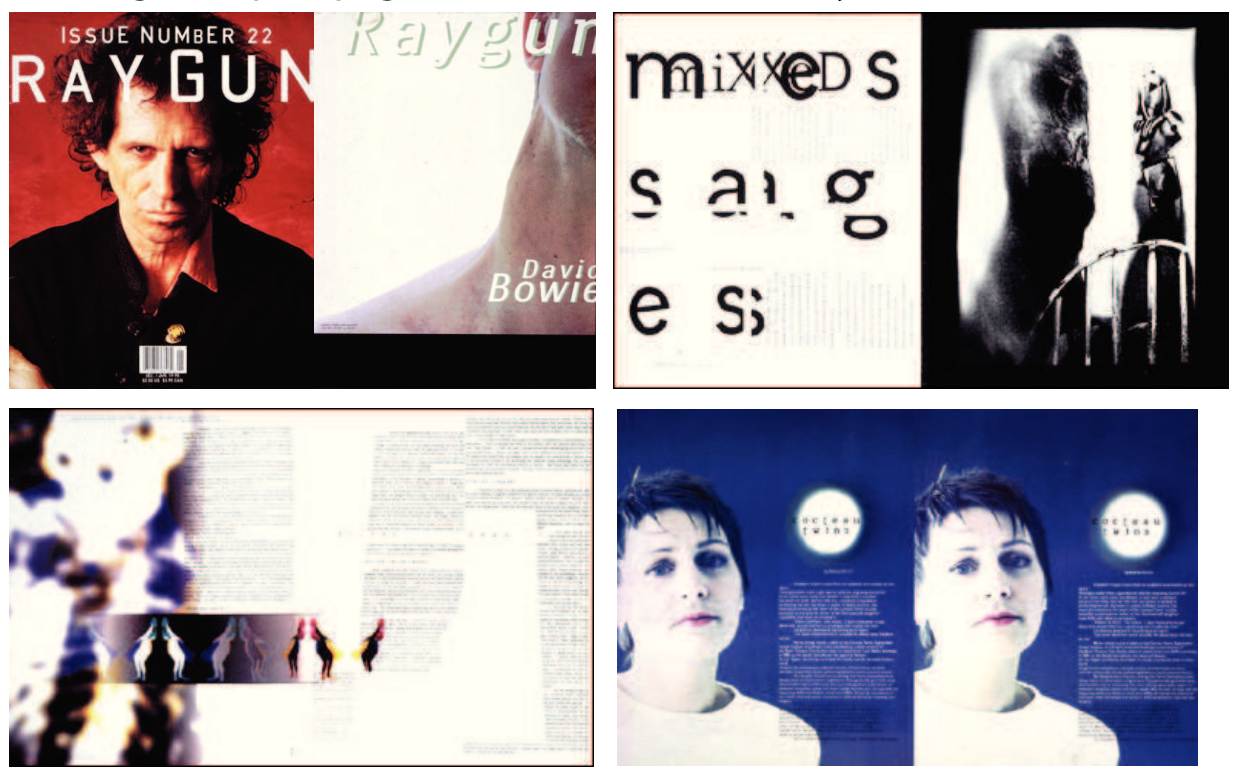

Fonte: website David Carson Design.

A revista Big, editada em Nova lorque e impressa na Espanha, também segue essa tendência. Sendo distribuída por vários países, sua estratégia é ser multicultural. A tipografia de seu logotipo varia de edição para edição, bem como sua localização na página (Fig. 6). Kopp (2004) cita ainda a revista mexicana Matiz e a revista brasileira Sexta Feira, entre outros exemplos de design gráfico cambiante na área editorial. 
Fig. 6: Capas da Revista Big, respectivamente números 25, 28, 29, 31 e 35.
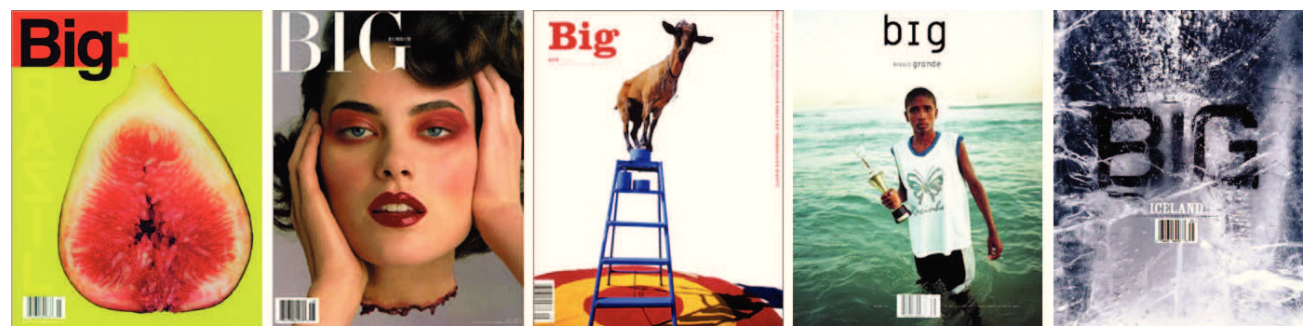

Fonte: website oficial da revista Big.

Kopp (2004) destaca dois casos na área de identidade visual: o logotipo do Jornal Literatur in Köln, Lik, criado em 1974 pela agência alemã GGK, e o logotipo MTV - Music Television (primeiro canal 24hs dedicado à música e voltado para público jovem), concebido em 1981 pelo estúdio Manhattan Design. O projeto do logotipo Lik (Fig. 7) foi na contramão do que estava sendo projetado no início dos anos 1970 e consiste um marco de design cambiante. Seu logotipo possuía várias versões, sendo apresentada cada letra em uma fonte diferenciada.

Fig. 7: Variações do logotipo Lik.

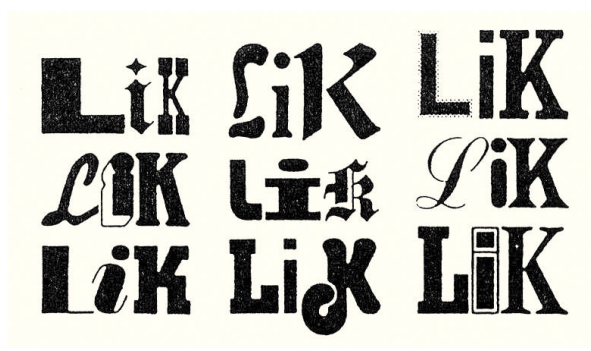

Fonte: Kopp (2004, p.95).

Já o logotipo MTV era composto por uma letra " $M$ " sugerindo tridimensionalidade e expressa em negrito e sem serifa, a abreviatura " $t v$ " era apresentada como sobreposta à letra, com tipografia em estilo manuscrito. $\mathrm{O}$ aspecto cambiante desta marca ocorria a partir de suas aplicações (Fig. 8), que poderiam acontecer das formas mais inusitadas possíveis, com texturas diversas em que o logo se investia de diferentes personalidades. 
Fig. 8: Variações do logotipo da empresa MTV.
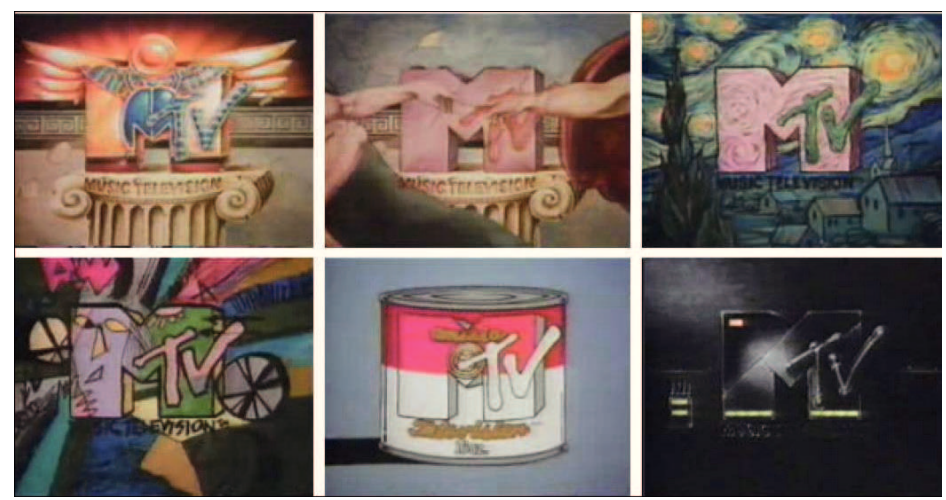

Fonte: Teixeira (2006, p.158).

O projeto de identidade visual da empresa MTV fazia parte de uma estratégia mais ampla do grupo multinacional de entretenimento ViaCon Inc. que, baseando-se em pesquisas de mercado, percebeu o potencial de consumo de um público jovem ávido por novidades (PONTE \& NIEMEYER, 2009). Kopp (2004), a programação visual e comunicativa MTV não consegue manter "uma coerência ou uma linha de pensamento una" e, também, cita Ann Kaplan, que considera essa comunicação como uma "torrente de significantes embaralhados e febris para os quais nenhum significado é pretendido ou tem tempo de ser comunicado.

Diferentemente do que informam Anna Kaplan e Rudinei Kopp, notase, ao assistir o canal, que mesmo se utilizando de um design cambiante, a identidade visual da MTVérapidamenteidentificada por seus telespectadores, o que significa que mesmo com uma profusão de imagens e uma aparente incoerência visual, há uma significação forte que é transmitida. Como afirma Machado (2003), "o canal da MTV é o mais facilmente reconhecível, é o que tem a mais forte 'identidade' na televisão, graças sobretudo à sua estética convulsiva e indomesticável, à sua ênfase na edição rápida e um certo surrealismo pop, que permitiu uma vez à empresa definir-se a si própria como the only that advertises itself as a fool (a única que anuncia a si mesma como uma doida)".

\section{IDENTIDADE VISUAL CAMBIANTE E FIXAÇÃO DAS CRENÇAS}

O sucesso da marca MTV com seu público mostra que não apenas uma identidade visual tradicional nos moldes do alto modernismo, baseado 
em elementos fixos e normas de aplicação, pode fixar crenças em seus consumidores. Dentro de uma proposta de um design cambiante, que aplica o logotipo (Fig. 9) com as mais variadas texturas e cores, podemos perceber que ainda há algo de regular que subjaz à diversidade: a estrutura do logotipo e a relação entre suas partes.

Fig. 9: Logotipo da MTV.

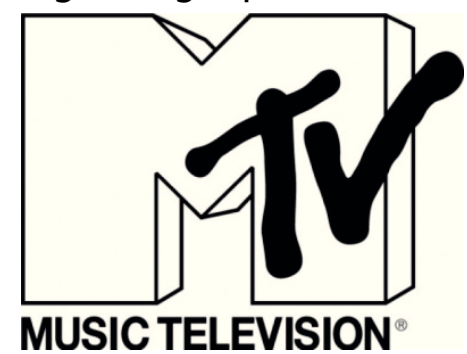

Fonte: Kopp (2004, p.96).

Independentemente do contexto em que o logotipo se insere, como pode ser visto na imagem anterior (Fig. 8), mantém-se a relação entre os elementos: há sempre a letra " $\mathrm{M}$ " com a abreviatura "tv", sugerindo estar parcialmente sobreposta ao lado esquerdo da letra. A teoria Gestalt, surgida no início do século XX na Alemanha, tratou da percepção visual, sugerindo que a primeira sensação é a forma, global e unificada, que decorre da estrutura do cérebro e dos estímulos objetivos. Assim, a análise de uma forma dependeria das características do objeto e das tendências naturais do cérebro em estabelecer certas relações (FILHO, 2002). Uma das suas principais leis é justamente a unificação e a segregação, que faz com que percebamos estímulos visuais como partes de um único elemento ou como partes de elementos distintos. Isso também faz com que consigamos distinguir cada objeto em si, independente das suas partes componente.

Desta forma, o logotipo da empresa MTV apresenta uma estruturação muito forte, que, mesmo aplicada de forma diferente em cada circunstância, continua identificável. Esse também é o caso do logotipo da cidade australiana de Melbourne (Fig. 10), que expressa de forma pregnante a letra " $\mathrm{M}$ ", independentemente do tratamento interno, gráfico e cromático, permanecendo facilmente discernível. Comunica-se, desta forma, a diversidade na aparência, mas a configuração ou contorno externo é mantido de maneira fixa. 
Fig. 10: Logotipo da cidade de Melbourne e sua identidade cambiante.

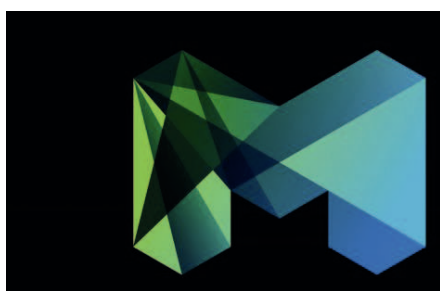

CITY OF MELBOURNE

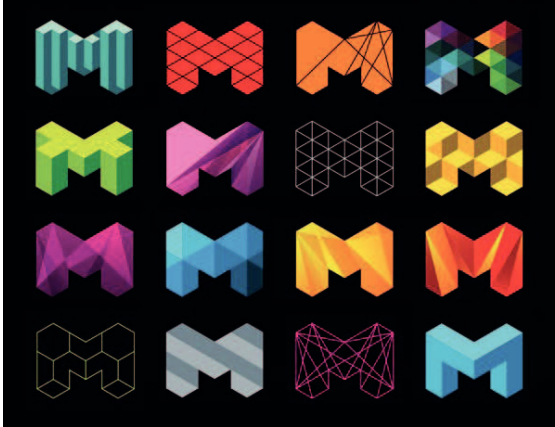

Fonte: Website City of Melbourne.

Algumas aplicações do logotipo da empresa Google são exemplos interessantes de sua identidade visual cambiável que, também, consegue fixar crenças e ser facilmente identificada, como signo que representa os conceitos de marca da empresa. Desde 1998, o website de busca Google apresenta doodles (Fig. 11), que são ilustrações ou vinhetas gráficas compostas com o seu logotipo e outros elementos decorativos ou temáticos de datas comemorativas e eventos.

Fig. 11: Doodles Google: (A) Aniversário de Kafka; (B) Festival Dragon Boat; (C) Dia de Portugal; (D) Dia do Professor.

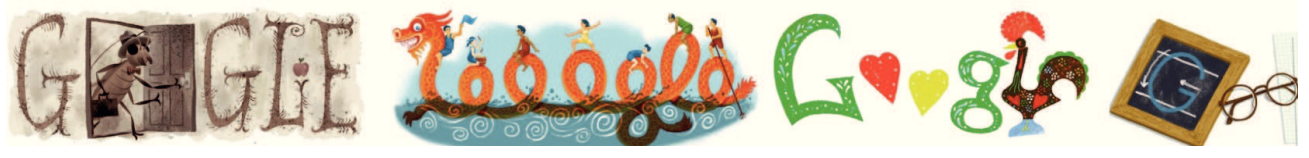

Fonte: website Doodles.

Nos doodles propostos (Fig. 11), buscou-se assemelhar os desenhos aos caracteres do logotipo Google, de forma mais ou menos evidente. Percebese que nas imagens relacionadas com a comemoração do aniversário do escritor Kafka e com o Dia Nacional de Portugal, a leitura do nome da empresa é mais clara, sendo que nas imagens relativas ao Festival Dragon 
Boat e, mais especificamente, ao Dia do Professor, há uma maior dificuldade perceptiva em discernir as letras. Há casos em que o contexto da página do website é o elemento que força a associação com o logotipo Google. O fato do internauta estar conectado ao website Google e habituado ao costume da empresa apresentar doodles criativos, o predispõe a interpretar os elementos de maneira associada ao logotipo, mesmo porque o doodle substitui o logotipo, ocupando a mesma localização na página. Por mais diferentes que os elementos visuais sejam desses caracteres, a percepção do internauta é forçada a procurar a conexão. Portanto, continua-se a fixar a crença, uma vez que o design cambiante torna-se previsível (ainda que não se saiba como irá se materializar).

\section{CONCLUSÃO}

Percebemos com esses exemplos que não apenas uma identidade visual mais tradicional, moldada ao estilo do alto modernismo, pode fixar crenças em seus consumidores. Ainda que uma marca possa ser representada visualmente de forma cambiante, com maior variedade de aplicações que se costuma projetar comumente, há algo estável nela que subjaz à variedade aparente, seja a forma, as relações entre os elementos ou mesmo o hábito que se estabelece na mente do consumidor, de que a empresa será representada de forma variada, criando a expectativa da sua ocorrência.

A identidade visual, incluindo a cambiante, deve fortalecer os valores e os conceitos de marca. Por isso, busca-se a fixação de crenças positivas a respeito da empresa representada. A criação de cada signo (logotipo ou assinatura visual) buscará uma estratégia própria e a escolha de uma identidade visual cambiante ou fixa dependerá, não apenas dos conceitos de marca a serem transmitidos, mas também da avaliação da adequação do projeto ao seu público-alvo. Podemos perceber que as empresas citadas neste artigo que apresentaram uma identidade visual cambiante mantêm um posicionamento conceitual ligado a valores como: contemporaneidade, juventude e transformação, visando como público-alvo consumidores interessados nesse posicionamento e nessas variações, como potenciais interessados nos seus produtos, serviços e ideias.

Portanto, ainda que a forma de apresentação do logotipo ou da assinatura visual possa mudar em diversas aplicações, transmitindo um dinamismo maior que a identidade visual tradicional, mostra-se 
fundamental desenvolver uma conceituação sólida para a marca cambiante, a partir da definição clara da estratégia do produto ou serviço, dos desejos e das necessidades do seu público-alvo, e da pesquisa dos concorrentes no mercado. $O$ projeto de design de uma identidade visual cambiante deve manter a mesma solidez de uma tradicional, e os conceitos de marca devem se materializar, buscando uma base estável que estruture os elementos mutáveis, como vimos nos exemplos ao longo do artigo. Somente assim a identidade visual cambiante de um produto ou serviço conseguirá se manter coerente em relação aos conceitos de marca e fixar crenças em seus consumidores.

\section{NOTAS}

[1] Um das estratégias no mundo capitalista para aumentar o lucros das empresas - objetivo final de qualquer companhia que esteja sob a lógica de mercado - é a aplicação da obsolescência programada. Seja pelo uso de materiais menos duráveis nos produtos, seja pela escolha de uma estética conectada a modismos, o intuito da obsolescência programada consiste em reduzir o ciclo de vida do produto por seu desgaste físico mais acelerado ou pelo seu descarte decorrente de uma estética que rapidamente torna-se ultrapassada.

\section{REFERÊNCIAS}

GOMES FILHO, João. Gestalt do objeto. 2. ed. São Paulo: Escrituras, 2002. GONÇALVES JÚNIOR, A. O. A.; FERREIRA, M. A. Estratégia de Obsolescência

Programada: uma Análise das Consequências Ambientais e Sócio-Econômicas. In: Administração de Empresas em Revista, Curitiba, n.9, p. 9-25, 2009-2.

MANUAL DA MARCA VALE. Disponível em www.vale.com. Consultado em 30 jul 2013.

HARVEY, David. A condição pós-moderna. 16 ed. São Paulo: Loyola, 2007.

IDENTIDADE CAMBIANTE: City of Melbourne. Disponível em http://rudineikopp. blogspot.com.br/2009/09/identidade-cambiante-city-of-melbourne.html. Consultado em 30 jul 2013.

KOPP, Rudinei. Design gráfico cambiante. Santa Cruz do Sul: EDUNISC, 2004.

MACHADO, Arlindo. A televisão levada a sério. 3. ed. São Paulo: Senac São Paulo, 2003. 
NIEMEYER, L. Elementos de semiótica aplicados ao design. 2. ed. Rio de Janeiro: 2AB, 2007.

PEIRCE, C. S. The Fixation of Belief. In: Popular Science Monthly 12. November 1877. p. 1-15.

PONTE, R.; NIEMEYER L. Identidade Corporativa e Fixação das Crenças. In: 12 Encontro Internacional sobre Pragmatismo, 2009, São Paulo. Encontro Internacional Sobre Pragmatismo. São Paulo: Centro de Estudos do Pragmatismo, 2009. p. 5-82.

PONTE, R.; NIEMEYER, L. O insólito como identidade televisiva: as vinhetas da MTV. In: Flavio Garcia; Marcello de Oliveira Pinto; Regina Michelli. (Org.). O insólito em questão - Anais do V Painel Reflexões sobre o Insólito na narrativa ficcional / I Encontro Nacional Insólito como Questão na Narrativa Ficcional. 1ed.Rio de Janeiro: Dialogarts, 2009, p. 197-217.

POYNOR, R. Abaixo as regras: design gráfico e pós-modernismo. Porto Alegre: Bookman, 2010.

STRUNCK, G. Identidade visual: a Direção do Olhar. Rio de Janeiro: Europa, 1989.

TEIXEIRA, C. A Linguagem Visual das Vinhetas da MTV: Videodesign como Expressão da Cultura Pós-Moderna. Rio de Janeiro: PUC, 2006 (dissertação de mestrado).

WEBSITE BIG. Disponível em http://www.bigmagazine.com. Consultado em 30 jul 2013.

WEBSITE DAVID CARSON DESIGN. Disponível em http://www.davidcarsondesign. com/t/2001/08/10/raygun-magazine. Consultado em 30 jul 2013.

WEBSITE DOODLES. Disponível em http://www.google.com/doodles/finder. Consultado em 30 jul 2013.

Recebido em: 09/09/2014; Aceito em: 07/11/2014.

Esta obra foi licenciada com uma Licença Creative Commons.
Lucy Niemeyer é designer, Doutora em Comunicação e Semiótica pela PUC de São Paulo, Mestre em Educação pela UFF, autora de livros e artigos sobre design, palestrante nacional e internacional. Atualmente, dedica-se ao ensino e à pesquisa na ESDI/UERJ, onde leciona na Graduação e no Curso de Mestrado e Doutorado em Design.

Raquel Ponte é designer, doutoranda e Mestre em Design pela ESDIUERJ, com graduação em Comunicação Social - Cinema pela UFF e MBA em Marketing pela Puc-Rio. Atualmente leciona no curso de Comunicação Visual Design na EBA-UFRJ, onde é Professora Assistente. 